\title{
uMed: Your Choice - Conception of a Digital Game to Enhance Medical Ethics Training
}

Katsarov, Johannes ; Biller-Andorno, Nikola ; Eichinger, Tobias ; Schmocker, David ; Christen, Markus

\begin{abstract}
In this contribution, we present the conception of the serious moral game uMed: Your Choice for the training of medical students' moral sensitivity and resoluteness. First, we offer an overview of the moral competences that we aim to train through the game: an empathic concern for relevant groups; an awareness of one's susceptibility to biases and stress, moral schemas and scripts for automatized sensitivity under time pressure; a sensitivity to attitudes of moral disengagement; and skills for speaking up about ethical issues. Second, we present the educational game mechanisms and contents that we have selected and combined to achieve the desired learning outcomes: playing an intern at a clinic, learners deal with several cases, in which they have to interact with patients, patients' relatives, and co-workers. Their decisions, including the way they communicate, have immediate as well as delayed consequences, and players receive constant feedback in terms of three value categories (empathy, integrity, efficiency). Third, we discuss how we employ the game within our study program. We close with a discussion of a possible critique of our design and with an outlook on the further design process.
\end{abstract}

DOI: https://doi.org/10.1007/978-3-658-28175-5_13

Posted at the Zurich Open Repository and Archive, University of Zurich

ZORA URL: https://doi.org/10.5167/uzh-194177

Book Section

Accepted Version

Originally published at:

Katsarov, Johannes; Biller-Andorno, Nikola; Eichinger, Tobias; Schmocker, David; Christen, Markus (2020). uMed: Your Choice - Conception of a Digital Game to Enhance Medical Ethics Training. In: Groen, M; Kiel, N; Tillmann, A; Weßel, A. Games and Ethics : Theoretical and Empirical Approaches to Ethical Questions in Digital Game Cultures. Wiesbaden: Springer, 197-212.

DOI: https://doi.org/10.1007/978-3-658-28175-5_13 


\section{UMED: YOUR CHOICE -}

\section{Conception of a Digital Game to Enhance Medical Ethics Training}

Johannes Katsarov ${ }^{1}$, Nikola Biller-Andorno, Tobias Eichinger, David Schmocker, \& Markus Christen

\section{Chapter Summary}

In this contribution, we present the conception of the serious moral game UMED: YOUR CHOICE for the training of medical students' moral sensitivity and resoluteness. First, we offer an overview of the moral competences that we aim to train through the game: an empathic concern for relevant groups; an awareness of one's susceptibility to biases and stress, moral schemas and scripts for automatized sensitivity under time pressure; a sensitivity to attitudes of moral disengagement; and skills for speaking up about ethical issues. Second, we present the educational game mechanisms and contents that we have selected and combined to achieve the desired learning outcomes: playing an intern at a clinic, learners deal with several cases, in which they have to interact with patients, patients' relatives, and co-workers. Their decisions, including the way they communicate, have immediate as well as delayed consequences, and players receive constant feedback in terms of three value categories (empathy, integrity, efficiency). Third, we discuss how we employ the game within our study program. We close with a discussion of a possible critique of our design and with an outlook on the further design process.

Keywords (6-10): game-based learning, serious game, ethics, moral, education, training, bioethics, medicine, simulation, game mechanics

Citation: Katsarov, J. / Biller-Andorno, N. / Eichinger, T. / Schmocker, D. / Christen, M. (2020). uMed: Your Choice - Conception of a Digital Game to Enhance Medical Ethics Training. In M. Groen, N. Kiel, A. Tillmann, \& A. Weßel (Eds.), Games and Ethics (pp. 197-212), Berlin: Springer. DOI: 10.1007/978-3-658-28175-5_13

1 Corresponding Author: Johannes Katsarov, University of Zurich, Center for Ethics, Zollikerstrasse 117, CH-8008 Zurich, johannes_katsarov@hotmail.de

Katsarov et al., 2020 - uMed Conception - Final Manuscript 


\section{On the Potential of Serious Moral Games in Medical Training}

Ethics training is generally regarded as a key component in the education of health professionals (World Medical Association 1999). Yet, ethical scandals and reports of unethical behaviors in the health sector (e.g., under-/overtreatment of patients, therapy without consent, etc.), continue to be relatively frequent. Situational factors like a lack of resources or institutionalized conflicts of interest could certainly play an important role here, e.g., when physicians are not remunerated for the treatment options that would be most beneficial for patients. Still, further improving the competences of health professionals to recognize ethical issues and resolve them appropriately in practice is essential, including their ability to even recognize the deteriorating impact of institutionalized conflicts of interest and missing resources.

Currently, a wide array of methods is employed in (medical) ethics training, often with positive effects, as recent meta-analyses show (e.g., Watts et al. 2017). We suggest to further enhance the quality of medical ethics training through digital games. Well-designed digital games are known to enhance learners' motivation and study performance (Wouters et al. 2013). We propose that serious moral games, i.e., digital games for the promotion of moral development, can yield diverse benefits (see Figure 1; Christen, Faller, Götz \& Müller 2013). Among others, they can be designed to simulate complex situations, e.g., ones in which players are required to make decisions under uncertainty. They can allow players to try out different behaviors and can provide immediate as well as delayed feedback, thereby sensitizing players to relevant issues. Moreover, they provide a secure environment for learners to experiment, fail, retry and optimize their behaviors.

Katsarov et al., 2020 - uMed Conception - Final Manuscript 


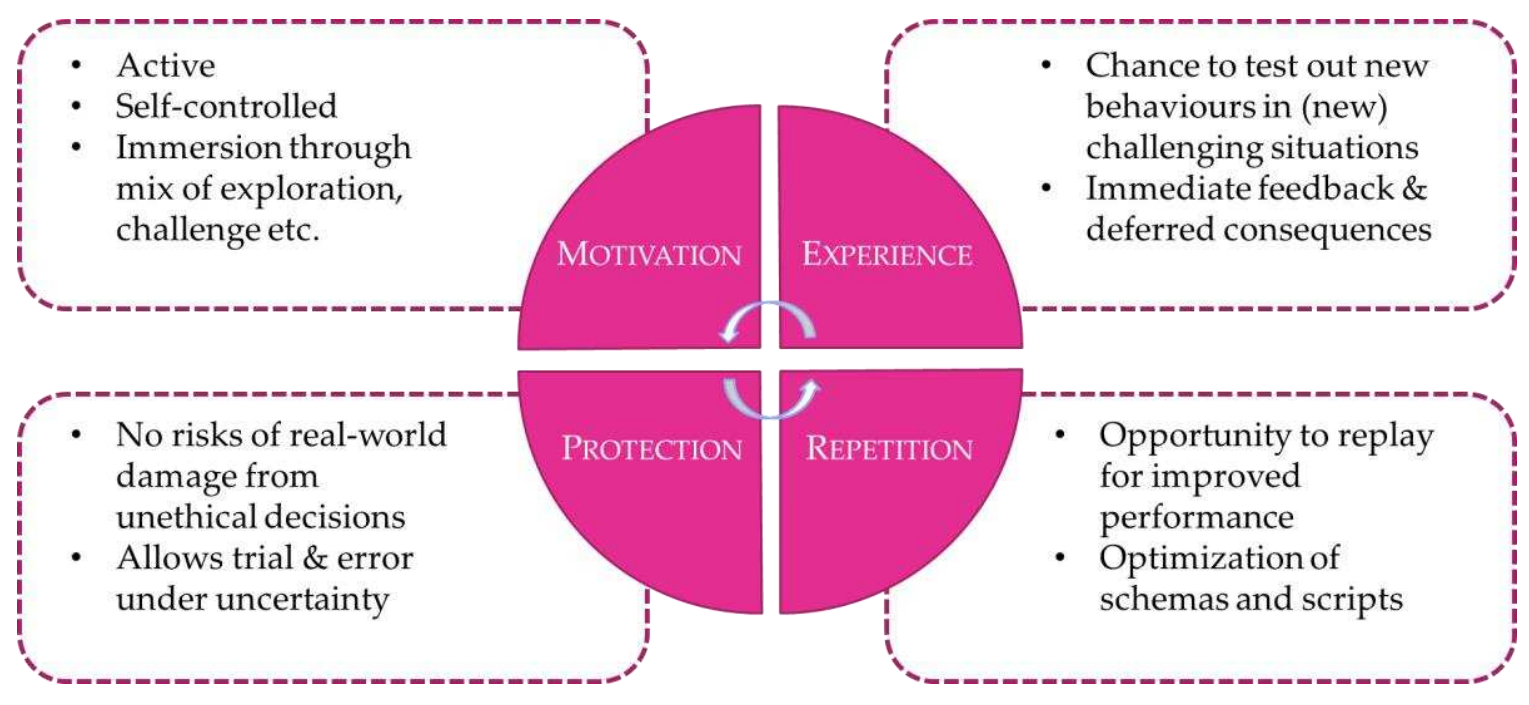

Figure 1: Value Proposition of Serious Moral Games (adopted and translated from Christen, M. \& Katsarov, J. (2018). Serious Moral Games - Videospiele als Werkzeuge der Ethikbildung. In T. Junge \& C. Schumacher (Eds.), Digitale Spiele im Diskurs, www.medien-im-diskurs.de, CC-BY).

\section{Desired Learning Outcomes of Training with UMED: YOUR CHOICE}

In the following, we will introduce the game UMED: YOUR CHOICE (UMED), developed by the authors in cooperation with the Swiss game studio Koboldgames and funded through the Swiss National Science Foundation and the University of Zurich. The aim of $U M E D$ is to complement existing approaches and resources of medical ethics training - not to replace good practices. The first step of our project was to identify the desired learning outcomes of $U M E D$ in consultation with experienced medical ethics trainers and clinical ethicists (two of whom are co-authors) in order to guide design, assess learning achievement and evaluate pedagogical approaches (cf. Joint Committee on Standards for Educational Evaluation 2011). We designed UMED for the purpose of reaching five learning outcomes, which are, in our experience, difficult to achieve within the tight curriculum typical of medical training. This chapter provides a short introduction of each learning outcome and its respective relevance.

The first four of these learning outcomes correspond with the competence of moral sensitivity as defined in diverse process models of moral agency (e.g., Rest 1982; Narvaez 2006; Tanner \& Christen 2014). Based on findings from moral psychology, Katsarov and Christen (2018) have identified these four components of moral sensitivity. The fifth learning outcome, moral resoluteness, corresponds with the final step of agency in diverse models, i.e., following through with what is seen to be right/good, and coping with different forms of resistance (Tanner \& Christen 2014). We suggest that both sensitivity and resoluteness are ideally

Katsarov et al., 2020 - uMed Conception - Final Manuscript 
trained through an approach of action-based learning, where learners envision the possible outcomes of different actions, make decisions, experience consequences and receive feedback (coping-modeling/problem solving, see below).

\subsection{Empathic Concern for Relevant Groups}

A key reason why medical professionals (and people in general) may act unethically is because they are ignorant of the specific needs of (some) people. What matters here is that medical professionals care for all relevant people with their interests and needs, so that they will relate to them, ask respectful and concerned questions, and anticipate what they may need and how they may be affected by one's actions. This caring attitude is commonly called empathic concern. Through exercises of adopting an affective perspective, i.e., imagining what a person might experience and feel in certain situations, empathic concern can even be developed for members of stigmatized groups (e.g., homeless people; (Batson et al. 1997). When people do not identify with people from certain groups, they do not adopt an affective perspective when thinking about members of these groups (Mitchell, Macrae \& Banaji 2006). People who have developed an empathic concern for people from certain groups tend to think about them more positively and will empathize with them more eagerly (ibid.). Drawing on Martin Hoffman's work, we expect that medical professionals with an empathic concern for all types of patients (including elderly people, migrants, people with drug addictions etc.) will be more likely to consider their needs (Hoffman 2000; Gibbs 2014).

\subsection{Awareness of Human Susceptibility to Biases and Stress}

A second reason why people tend to engage in unethical behavior is because they do not recognize how their assessment of situations can be biased in different ways. Studies show that a conflict of interest can affect our assessment of risks (making us overly optimistic or pessimistic), even when we are motivated to be objective (Bazerman \& Tenbrunsel 2011). Similarly, humans in general tend to ignore long-term effects (discounting-the-future bias), judge situations differently, depending on how they are framed (e.g., " $1 \%$ risk" vs. " $99 \%$ chance") etc. In the practice of medicine, time pressure is high, potentially leading to rash judgments, which are particularly prone to bias (Tversky \& Kahnemann 1974). Therefore, making medical professionals aware of their susceptibility to motivational biases is important. Effectively, they need to develop a level of professional skepticism regarding their own assessments and motivations (and

Katsarov et al., 2020 - uMed Conception - Final Manuscript 
those of colleagues), which allows them to remain critical and question the adequacy of their judgments and intentions regularly.

Whereas the previous learning outcome (empathic concern) leans more in the direction of an implicit, intuitive, fast cognitive process, this learning outcome (awareness) is more about a self-competence to critically evaluate and reflect upon one's judgments and perceptions (reflectivity).

\subsection{Moral Schemas and Scripts for Automatized Sensitivity under Time Pressure}

Awareness of how conflicts of interest and other motivational factors may distort perception is not sufficient to overcome relevant problems: A large part of human thinking is sub-conscious, intuitive and automatic, and people often lack the time and energy to double-check whether their assessments may be biased in some way or another. Hence, to overcome biased perceptions, people ideally develop scripted responses, which they will automatically activate any time they come across a relevant problem (category), and which incorporate moral dimensions (Bazerman \& Tenbrunsel 2011). For example, a medical professional who offers acupuncture for an extra fee could be biased to preferentially diagnose problems that can be treated through acupuncture. ${ }^{2}$ A scripted response to deal with such a conflict of interest could be for the physician to generally test all of his diagnoses by checking whether alternative explanations for the symptoms are also possible, and by asking follow-up questions to rule out a false diagnosis. ${ }^{3}$ Scripted responses are therefore evaluative schemas, which systematically direct the attention and behavior in certain situations (e.g., medical practice), and ensure that one is not overlooking anything relevant.

Professionals generally work with scripts and schemas, through which they automatize much of their behavior: What matters here, is that their schemas and scripts include moral dimensions, so that they take them into account routinely, instead of ignoring them (Gioia 1992; Seiler, Fischer \& Voegtli 2011).

\subsection{Sensitivity to Attitudes of Moral Disengagement}

Even when medical professionals generally care for other people, are aware of their human vulnerability to biases and stress, and have adopted diverse scripts

2 One of the authors experienced this case as a patient.

3 This example is meant to illustrate how a script is basically a routine procedure of doing something.

Katsarov et al., 2020 - uMed Conception - Final Manuscript 
and schemas that help them to notice moral issues routinely, they may still behave unethically in some situations if they hold morally disengaged attitudes. Attitudes of moral disengagement are generally rationalizations of unethical behavior, which allow people to ignore moral considerations in the first place (Bandura 1999). Morally disengaged attitudes can take many forms, including double standards, whereby the interests, needs, contributions and opinions of people from certain groups (e.g., women, elderly) are generally viewed as inferior. These attitudes do not necessarily need to be explicit. Often, they are, in fact, implicit attitudes, which their bearers are not aware of, and which they do not want to hold, e.g., implicit racism or sexism (cf. Banaji \& Greenwald 2013). Very often, morally disengaged attitudes concern routine activities, where professionals like to "cut corners", e.g., they do not take time to talk with patients about important matters because "they will forget anyway" etc. Bandura (1999) has identified six widespread types of moral disengagement (e.g., blaming the victim) through which people allow themselves to ignore moral aspects. One of our goals is to sensitize learners to such attitudes so that they will identify relevant rationalizations as problematic.

\subsection{Skills for Speaking Up About Ethical Issues}

Even when medical professionals are aware of ethical problems, e.g., the racial discrimination of a patient by a superior, they may fail to act in accordance with their values and professional ethical codes due to fear of repercussions (e.g., workplace harassment), in lack of appropriate responses and strategies, insecurity about an ethical issue and possible consequences of actions or perceived inferiority of experience (Raemer et al. 2016). Moral ownership, courage and efficacy are therefore important goals for ethics training: People who possess these three sub-components of moral potency are more likely to (1) feel the necessity to intervene in a relevant situation, (2) overcome relevant fears, and (3) feel confident in the ability to address relevant challenges, e.g., in persuading others (Hannah \& Avolio 2010). Following Mary Gentile, the development of relevant schemas and scripts will also be helpful here, e.g., finding it normal to speak about moral issues, or having good arguments ready to respond to common rationalizations of questionable behaviors (Gentile 2010).

\section{Selected Game Mechanisms and their Combination}

To promote the achievement of the desired learning outcomes, we have selected and combined several game mechanisms, i.e., aspects of the game that enable or

Katsarov et al., 2020 - uMed Conception - Final Manuscript 
frame the players' interaction with the game: "(1) possible actions and choices of players, (2) how these are framed (role, perspective, and goals), and (3) which consequences the players' actions and choices may have (feedback, rewards, etc.)" (Katsarov, Christen, Mauerhofer, Schmocker \& Tanner 2019, p. 347). Suitable game mechanisms were identified based on a previously published review of literature and digital games (ibid.). In the following, we describe how we have combined them and how they shall support relevant learning.

\subsection{Personalization and Realism}

A central challenge for (game-based) learning lies in the transfer of what has been learned (knowledge, skills etc.) to the relevant practice. To facilitate transfer, we have decided to place the narrative of our game in a relatively realistic setting. This makes the game experience meaningful for our main target group, students of medicine, and will therefore help to foster the learners' motivation to engage in the game and reflect on their experience of it. Players slip into the role of a recent graduate of medicine starting their residency (a first job as an assistant doctor) at a regional hospital.

At the beginning of the game, players can choose their name and gender so that they can identify with the role they are playing, or expressly choose to play someone other than themselves. In accord with qualitative findings, both forms of experience will be meaningful and can foster moral development (Consalvo, Busch \& Jong 2019). Moreover, in a recent meta-analysis Mayer (2014) has found that the personalization of game-based learning strongly increases instructional effectiveness.

\subsection{Awarding of Points}

The game's introduction aims at acquainting players with the narrative (role and mission) and at introducing a central game mechanism.

After a short prologue, players encounter their future supervisor, a leading physician at the clinic where they are performing their residency. She invites players to do their best, offering them a permanent position if they prevail. Also, she introduces them to the three types of points that are awarded to players (see below). The back-story is that all staff members of the clinic are currently receiving $360^{\circ}$ feedback through a new system on three aspects: empathy, integrity and efficiency (cf. Table 1). She makes it clear that the player's scores will be decisive in the player's final evaluation.

Katsarov et al., 2020 - uMed Conception - Final Manuscript 
What players do not know is that the purpose of these three value dimensions is to highlight how different values and expectations may collide and conflict in practice. The efficiency dimension is meant to work as a distractor: It creates conflicts of interest, making it costly to engage in compassionate and courageous actions for players, i.e., without losing efficiency points. For instance, players might find themselves in the situation that they want to look up alternative explanations for the problems a patient is facing - yet losing efficiency points while using the office computer to do so. Similarly, players may not be able to perform their tasks very efficiently without losing empathy and integrity points (at least in the short term). We also create trade-offs between empathy and integrity to demonstrate to players that morally good goals can also collide in practice. Yet, the main goal is to sensitize learners for the fact that conflicting values are part of medical practice and that a certain balance is necessary. Overall, this game mechanism shall promote the development of moral schemas in learners and sensitize them to the power of motivational biases.

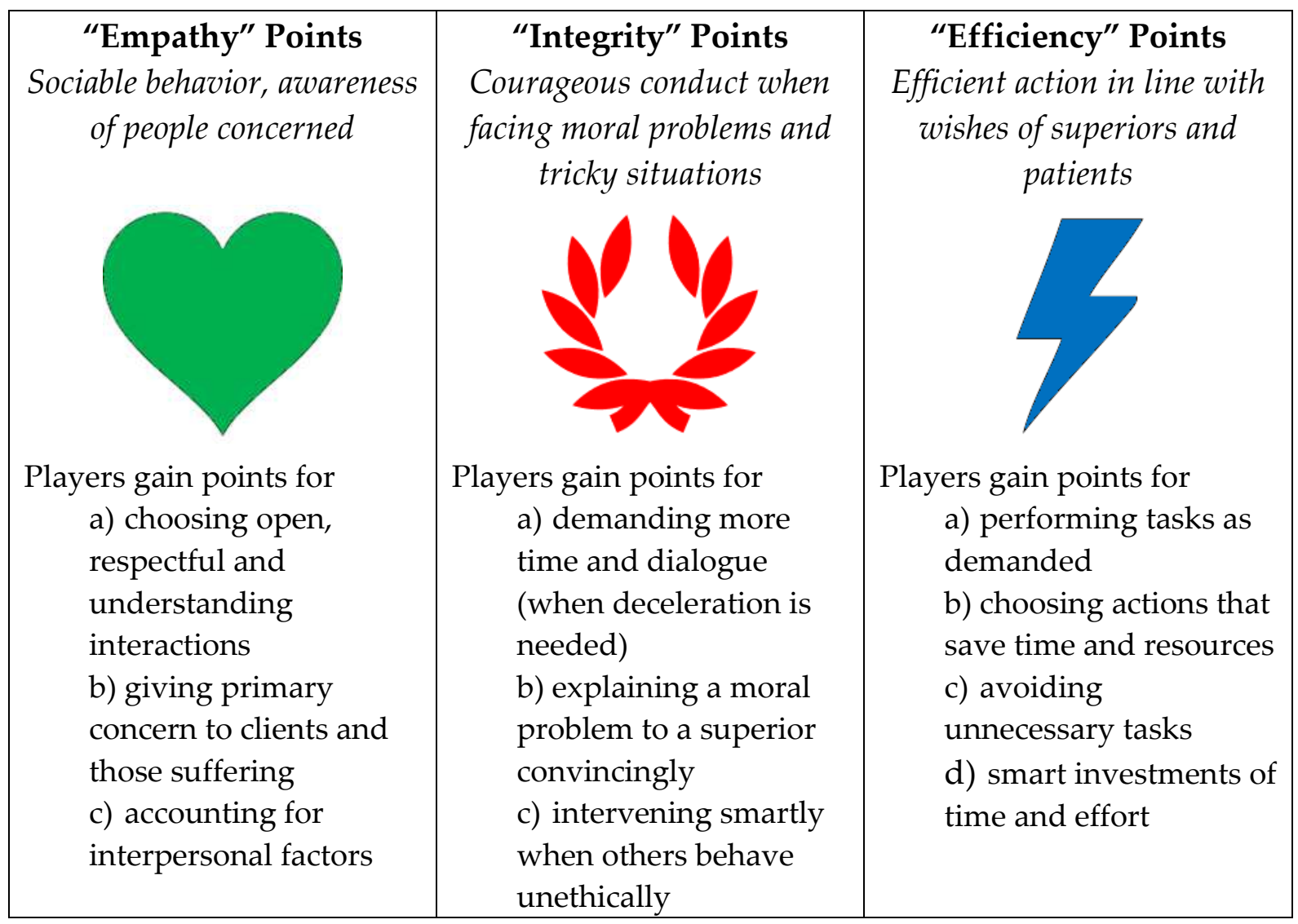

Table 1: Points awarded for three conflicting value dimensions.

Katsarov et al., 2020 - uMed Conception - Final Manuscript 


\subsection{Activities, Decisions and Consequences}

Following the introduction, players choose one of several cases to play, three of which have already been written by Johannes Katsarov, Sandra Rossi, and Maika Schelb. Each case represents a scenario with one patient, his/her relatives (if available) and other staff of the clinic. The players interact with these non-playable characters (NPCs) by selecting from diverse dialogue options. Depending on the players' choices, the scenario unfolds in different ways (branched storyline). Many decisions only have an impact in terms of the points that players win or lose. However, the game is programmed in a way that even seemingly "minor" choices have an impact on the outcome of the narrative (inspired by the "systemic approach" to engaging ethical expertise in digital games discussed by Formosa, Ryan \& Staines 2016).

At the micro level, players exercise their communicative skills in working with the NPCs, e.g., an elderly woman who has suffered a stroke and who is rejecting her treatment. ${ }^{4}$ Each scenario confronts players with a prevalent conundrum of biomedical ethics (e.g., allocation problems, advance care planning, or shared decision-making). For instance, players can test their own abilities to assess the elderly woman's judgment. The goal is to sensitize players for the practical relevance of the skills that are developed as part of medical ethics training and to offer them cases to experiment with. By portraying some of the fictional patients negatively, e.g., as naïve, we make it more difficult for players to exercise ethical skills and tempt them to arrive at false conclusions or to "cut corners" (e.g., having a naïve patient sign a letter of consent without understanding the risks of an operation). The educative strategy, which we employ, is a variation of the coping-modeling/problem-solving approach (cf. Simola 2010). We do not present ethically relevant decisions to players overtly. Instead, more or less ethical behaviors present themselves subtly, at the level of nuances (e.g., whether players choose to ask a patient what is important to her or assume that they already know what is best). In presenting dialogue options, we contrast praiseworthy and problematic alternatives, challenging learners to identify relevant differences autonomously. Since players expect immediate feedback and delayed consequences of their choices, they are also motivated to analyze the

4 The game does not demand medical knowledge from players. Relevant information on diagnoses, treatments etc. will be readily available so that the game can also be played by medical laypeople.

Katsarov et al., 2020 - uMed Conception - Final Manuscript 
options, thereby searching for noteworthy differences. In doing so, they ought to exercise and improve their moral schemas because they are building associations between empathy (caring, patient orientation), integrity (concern for justice, patient autonomy, etc.) and efficiency with different behavioral options (including the use of language and other forms of communication, e.g., raising one's voice or comforting an elderly patient by holding her hand).

At the meso level, players face diverse critical incidents (critical decisions) over the course of the game. In some of these incidents, players experience conflicts of interest, which are either subtle or obvious, and which are either personal (beneficial to the player) and/or institutional (beneficial to the clinic or medical team). For instance, one of the scenarios features a seemingly rich foreigner, the overtreatment of whom promises an extra income for the hospital and a personal gratification for the player. In these cases, players need to sacrifice some benefit at least in the short term - to act ethically. In featuring these problems, we also offer players seemingly good justifications to act unethically, e.g., rumors that the rich foreigner is a warlord and that he has made his apparent fortune by selling weapons. Each critical scenario forces the players to make more or less explicit decisions with consequences for the further story. Through this setup, we aim to sensitize players to attitudes of moral disengagement and motivational biases, but also challenge them to exercise moral courage and recognize strategies for doing so effectively.

At the macro level, the different scenarios unfold over several days, adding gravity to the critical decisions of players. One scenario may go on, for instance, over a total of three days. Based on the final decision of the first day, players engage with one of three different narrative branches on the following day, with several different outcomes for the scenario on the final day. In the long run, unethical actions have negative repercussions for the players, mostly in terms of consequences for the patients (outcomes of therapy). In some cases, the players will be reprimanded for these consequences, e.g., if they lead to financial losses for the clinic. In other cases, the players are not (only) criticized by NPCs, but (also) witness the negative outcomes of their decisions. Ethical decisions, on the other hand, generally have positive outcomes at the narrative level of the game, although these players may have collected fewer performance points than others and may be criticized in the short term.

Katsarov et al., 2020 - uMed Conception - Final Manuscript 
The macro level pursues two main goals. On the one hand, it shall sensitize players to the dangers of short-term (efficiency) thinking, thereby fostering positive attitudes towards taking enough time to work with patients and their relatives. On the other hand, the scenarios are designed to ensure that players must build positive relationships with the patients (and their relatives) in order to be successful. To build these relationships, they need to make efforts to understand these characters and relate to them as humans. The purpose is to engage players in affective perspective taking and an expansion of the group of people with whom they can identify affectively. Players who take enough time will learn a lot about the lovable features of their patients, e.g., an elderly woman's dedication to her (grand) children and her love of birds.

The micro, meso and macro levels are connected in the game. A biased or otherwise problematic communication with an NPC at the micro level could lead to a poorly informed decision at the meso level with negative consequences at the macro level.

\subsection{Final Feedback}

At the end of each case, players find out how the scenario has unfolded through a presentation of outcomes and during a personal development session with their supervisor, the leading physician. She first comments on the points scored by the players $\left(360^{\circ}\right.$ feedback), offering positive and negative feedback. Then, based on how the case was handled, she will highlight praiseworthy and problematic behaviors. To promote moral ownership and efficacy, it is important to show learners how their choices and decisions matter, and how they can influence the course of events (Hannah \& Avolio 2010). For this reason, the leading physician's feedback focuses on the impact of specific decisions and behaviors of players, who can then react in different ways.

\section{Use of the Digital Game in Study Programs}

At the University of Zurich, all approx. 400 sixth-semester medical students participate in a course in clinical ethics. We are currently redesigning this course to work with UMED. The course is held in small groups of 10-13 students and is structured in four units of 90 minutes. So far, standard procedure for these sessions has been for a lecturer to shortly introduce the topic of the unit, followed by the main part of the course: a mentored discussion of clinical cases with ethical problems or dilemmas.

Katsarov et al., 2020 - uMed Conception - Final Manuscript 
Two years earlier, in their first semester, all medical students have already been introduced to medical ethics, also in small groups. In the introductory course, a new e-learning tool is now being administered: This e-tool imparts theoretical foundations of medical ethics as well as an introduction to clinical ethics in the form of a structured case-discussion model (basic knowledge + practical exercises). It can be used individually, e.g., at home and in the classroom together with the group. The e-tool is meant to support medical students throughout their studies.

$U M E D$ is now being integrated into the design of this third-year course. Before each of the four units, students are required to play one case of the game (on their own or in teams). After completing the case, they have to write a short report on their playing experience based on three reflective questions (homework assignment). On the basis of these reports, the teachers will address remarkable thoughts concerning the critical topics (power of judgment, allocation problems, informed consent, and shared decision-making) in the following sessions. The teachers will show how the gamified scenarios correspond with ethical theory and skills and discuss the different behavioral options the game offers with the students. At this point, different components of the e-tool will also be re-utilized alongside newly created teaching materials with explicit game references (in form of screenshots of key scenes), with the aim of applying theory to practice and supporting the students in internalizing the relevant methods.

\section{Discussion}

A frequently raised point of criticism of our approach is that the game evaluates players' behaviors. We are then asked to justify why certain actions are evaluated one way or another, and why some actions have positive consequences, while others do not. In part, this point of criticism may be based on the notion that ethics teachers (and teachers engaged in political education) should take an impartial stance and facilitate discussion among the students as equals, without abusing their authority to impart their own values to the students (Lee 2006). We generally concur that ethics trainers need to be wary of this; not because "value neutrality" is desirable (it is neither desirable nor possible), but because mutual respect, value plurality, tolerance of diversity, and autonomous/critical thinking are important values to be upheld in constitutional democracies and professional practices: An implicit requirement of ethics training is for trainers to endorse

Katsarov et al., 2020 - uMed Conception - Final Manuscript 
values like these and role-model appropriate behaviors in doing so (cf. Hand 2018).

Therefore, we take this concern seriously. There are two reasons why we have still decided to evaluate players' decisions and actions in the game. First, it is a fact of life that our actions and behaviors are evaluated by ourselves and others. The main difference between our system and real life is that players receive immediate feedback on almost all of their decisions (through the awarding of points, and partially through reactions), which is not always the case in real life. Yet, for the educational purposes of our game, the immediate awarding (or loss) of points appears to be prudent. It sensitizes players for the value dimensions in practice. Additionally, we do not regard it as problematic if players or lecturers disagree with some of the evaluations of the game: The evaluations are portrayed as subjective $360^{\circ}$ feedback from patients, their relatives, and co-workers, not as objective statements made by a moral expert. In fact, disagreement about evaluations can foster valuable discussions about what constitutes ethical practice, and thereby contribute to students' moral development.

Second, our game might be considered more just than real life, because it generally rewards ethical actions (at least in the long run) and punishes unethical conduct (at least in the long run, e.g., by making players experience the consequences of their decisions). In reality, unethical actions like unnecessary treatments do not necessarily end in disaster. They do sometimes, however. Effectively, this means that we have removed moral luck from our stories to some degree and introduced some kind of "cosmic justice". Since a central aim of our game is to sensitize people for ethical risks, including an awareness of egoistic biases that may lead us to overly optimistic/pessimistic risk perceptions, we suggest that the "moralist" consequences in our game are justified and beneficial to relevant learning.

\section{Outlook}

$U M E D$ is currently undergoing a process of rigorous testing and continuous improvement. Six teachers have already experimented with the first two cases of the game in teaching approximately 85 third-year students during the spring semester 2019. Additionally, we have conducted quantitative laboratory experiments with two cases of the game and experimented with different game instructions in a qualitative study (with the third case). Following good practices of user experience research (Hodent 2018), our investigations concern the game's

Katsarov et al., 2020 - uMed Conception - Final Manuscript 
usability and engageability, the emotions, judgments and reflections inspired in players, and the game's effectiveness in achieving the desired learning outcomes. ${ }^{5}$ First findings are expected to be published in 2020.

In terms of continuous improvement, we are revising several features of the game. For example, in a previous version the game included a mentor, who challenged players to identify positive and negative aspects of their working environment. We gave up this game mechanism, since it did not appear to add value. We have also just implemented an online system for the game, which was previously played offline on players' own computers. This online system allows us to collect anonymized statistical information about the in-game decisions of the learners. This information will support the game's further improvement but may also be useful in helping teachers address specific topics in their groups. ${ }^{6}$ Another innovation that we will test soon is the inclusion of "achievements", which players can collect for certain actions and outcomes and which might inspire them to play the game several times to explore more of the different options. Finally, we are currently investigating different teaching strategies of working with the game, e.g., whether players learn more when they play it alone or in groups.

Once the game has been validated and reached a sufficient degree of sophistication, we want to make it widely accessible for medical ethics training, including interprofessional ethics training and further education.

\section{Bibliography}

Banaji, M. R., \& Greenwald, A. G. (2013). Blindspot: Hidden Biases of Good People. New York: Delacorte.

5 For instance, we have optimized a previously published test of value sensitivity in medicine (Ineichen et al. 2017) and used this instrument for pre- and post-tests with players and control groups.

6 The anonymization of the player data is crucial: It ensures the safe space that allows for the students to learn by trial and error and to play with the ethical scenarios, which can even include the imagination of antisocial behaviors. Disclosing personal player data to lecturers and group members could lead to the attribution of blame or the stigmatization of learners. If students choose to share and discuss their own game experiences and decisions, they should be able to do this at their own will.

Katsarov et al., 2020 - uMed Conception - Final Manuscript 
Bandura, A. (1999). Moral Disengagement in the Perpetration of Inhumanities. Personality and Social Psychology Review, 3(3), 193-209.

Batson, D., Polycarpou, M., Harmon-Jones, E., Imhoff, H., Mitchener, E., Bednar, L., Klein, T., \& Highberger, L. (1997). Empathy and Attitudes: Can Feeling for a Member of a Stigmatized Group Improve Feelings Toward the Group? Journal of Personality and Social Psychology, 72, 495-509.

Bazerman, M., \& Tenbrunsel, A. (2011). Blind spots: Why We Fail to Do What's Right and What to Do About It. Princeton, NJ: Princeton University Press.

Christen, M., Faller, F., Götz, U. \& Müller, C. (2013). Serious Moral Games. Analyzing and Engaging Moral Values Through Video Games. Zurich: Zurich University of

Arts (https://www.encyclog.com/ upl/files/SeriousMoralGames English Final.pdf).

Christen, M., \& Katsarov, J. (2018). Serious Moral Games - Videospiele als Werkzeuge der Ethikbildung. In: T. Junge \& C. Schumacher (Eds.), Digitale Spiele im Diskurs. www.medien-im-diskurs.de.

Consalvo, M., Busch, T., \& Jong, C. (2019). Playing a Better Me: How Players Rehearse Their Ethos via Moral Choices. Games and Culture, 14(3), 216-235, DOI: $10.1177 / 1555412016677449$

Formosa, P., Ryan, M., \& Staines, D. (2016). Papers, Please and the systemic approach to engaging ethical expertise in video games. Ethics and Information Technology, 18, 211-25. doi:10.1007/s10676-016-9407-z

Gentile, M. (2010). Giving Voice to Values. How to Speak Your Mind When You Know What's Right. New Haven / London: Yale University Press.

Gibbs, J. (2014). Moral Development and Reality. Beyond the Theories of Kohlberg, Hoffman, and Haidt ( ${ }^{r d}$ ed.). Oxford: Oxford University Press.

Gioia, D. (1992). Pinto Fires and Personal Ethics: A Script Analysis of Missed Opportunities. Journal of Business Ethics, 11(5), 379-89.

Hand, M. (2018). A Theory of Moral Education. Oxon: Routledge.

Hannah, S., \& Avolio, B. (2010). Moral Potency: Building the Capacity for Character-based Leadership. Consulting Psychology Journal: Practice and Research, 62(4), 291-310.

Katsarov et al., 2020 - uMed Conception - Final Manuscript 
Hodent, C. (2018). The Gamer's Brain. How Neuroscience and UX Can Impact Video Game Design. Boca Raton et al.: CRC Press.

Hoffman, M. (2000). Empathy and Moral Development: Implications for Caring and Justice. Cambridge: Cambridge University Press.

Ineichen, C., Christen, M., \& Tanner, C. (2017). Measuring Value Sensitivity in Medicine. BMC Medical Ethics, 18(5).

Joint Committee on Standards for Educational Evaluation (2011). The Program Evaluation Standards (3 ${ }^{\text {rd }} e$ d.). Thousand Oaks: Sage.

Tversky, A., \& Kahnemann, D. (1974). Judgment Under Uncertainty: Heuristics and Biases. Science, 185(4157), 1124-31.

Katsarov, J., Christen, M., Mauerhofer, R., Schmocker, D., \& Tanner, C. (2019). Training Moral Sensitivity Through Video Games: A Review of Suitable Game Mechanisms. Games and Culture, 14(4), 344-66, DOI: 10.1177/1555412017719344

Katsarov, J., \& Christen, M. (2018). Promoting the Moral Sensitivity of Police and Military Personnel. NECESSE, 3(1), 114-20.

Lee, D. (2006). Academic Freedom, Critical Thinking and Teaching Ethics. Arts \& Humanities in Higher Education, 5(2), 199-208.

Mayer, R. E. (2014). Computer Games for Learning. An Evidence-Based Approach. Cambridge: MIT Press.

Mitchell, J., Macrae, C., \& Banaji, M. (2006). Dissociable medial prefrontal contributions to judgments of similar and dissimilar others. Neuron, 50(4), 65563, DOI:10.1016/j.neuron.2006.03.040

Narvaez, D. (2006). Integrative Ethical Education. In M. Killen \& J. Smetana (Eds.), Handbook of Moral Development (pp. 703-33). Mahwah, NJ: Erlbaum.

Raemer, D. B., Kolbe, M., Minehart, R. D., Rudolph, J. W., \& Pian-Smith, M. C. (2016). Improving Anesthesiologists' Ability to Speak Up in the Operating Room: A Randomized Controlled Experiment of a Simulation-Based Intervention and a Qualitative Analysis of Hurdles and Enablers. Academic Medicine, 91(4), 530-39, DOI: 10.1097/ACM.0000000000001033

Rest, J. (1982). A Psychologist Looks at the Teaching of Ethics. The Hastings Center Report 12(1), 29-36.

Katsarov et al., 2020 - uMed Conception - Final Manuscript 
Seiler, S., Fischer, A., \& Voegtli, S. (2011). Developing moral decision-making competence: A quasi-experimental intervention study in the Swiss Armed Forces. Ethics and Behavior, 21, 452-70.

Simola, S. K. (2010). Use of a "coping-modeling, problem-solving" program in business ethics education. Journal of Business Ethics, 96, 383-401.

Tanner, C., \& Christen, M. (2014). Moral Intelligence - A Framework for Understanding Moral Competences. In M. Christen, C. van Schaik, J. Fischer, M. Huppenbauer \& C. Tanner (Eds.), Empirically Informed Ethics. Morality between Facts and Norms (pp. 119-36). Cham: Springer.

Watts, L., Medeiros, K., Mulhearn, T., Steele, L., Connelly, S., \& Mumford, M. (2017). Are Ethics Training Programs Improving? A Meta-Analytic Review of Past and Present Ethics Instruction in the Sciences. Ethics $\mathcal{E}$ Behavior, 27, 351-84.

World Medical Association (1999). Resolution on the Inclusion of Medical Ethics and Human Rights in the Curriculum of Medical Schools World-wide. Tel Aviv: World Medical Assembly.

Wouters, P., van Nimwegen, C., van Oostendorp, H., \& van der Spek, E. (2013). A Meta-Analysis of the Cognitive and Motivational Effects of Serious Games. Journal of Educational Psychology, 105, 249-65.

Katsarov et al., 2020 - uMed Conception - Final Manuscript 
Johannes Katsarov

University of Zurich

Ethics Research Institute

Zollikerstrasse 117

CH-8008 Zürich

johannes.katsarov@uzh.ch

Prof. Dr. med. Dr. phil. Nikola Biller-Andorno

University of Zurich

Institute of Biomedical Ethics and History of Medicine

Winterthurerstrasse 30

CH-8006 Zurich

biller-andorno@ibme.uzh.ch

Markus Christen, PD Dr. sc. ETH

University of Zurich

Institute of Biomedical Ethics and History of Medicine

Winterthurerstrasse 30

$\mathrm{CH}-8006$ Zurich

christen@ethik.uzh.ch

Dr. Tobias Eichinger

University of Zurich

Institute of Biomedical Ethics and History of Medicine

Winterthurerstrasse 30

$\mathrm{CH}-8006$ Zurich

eichinger@ibme.uzh.ch

Dr. David Schmocker

University of Zurich

Institute of Banking and Finance

Plattenstrasse 32

$\mathrm{CH}-8032$ Zurich

david.schmocker@bf.uzh.ch

Katsarov et al., 2020 - uMed Conception - Final Manuscript 